\title{
Potential of the Parasitoid Tetrastichus howardi (Olliff, 1893) (Hymenoptera: Eulophidae) on the Control of Helicoverpa armigera (Hübner, 1805) (Lepidoptera: Noctuidae)
}

\author{
Juliana Simonato ${ }^{1}$, Harley N. de Oliveira ${ }^{2}$, José F. J. Grigolli ${ }^{1}$, Mirian M. Kubota Grigolli ${ }^{1} \&$ Ivana F. da Silva $^{3}$ \\ ${ }^{1}$ Fundação MS para Pesquisa e Difusão de Tecnologias Agropecuárias, Maracaju, MS, Brazil \\ ${ }^{2}$ Embrapa Agropecuária Oeste, Dourados, MS, Brazil \\ 3 Programa de Pós-graduação em Entomologia e Conservação da Biodiversidade, Universidade Federal da \\ Grande Dourados, Dourados, MS, Brazil
}

Correspondence: Ivana F. da Silva, Programa de Pós-graduação em Entomologia e Conservação da Biodiversidade, Universidade Federal da Grande Dourados, Dourados, MS, Brazil. E-mail: ivanaf.silva@hotmail.com

Received: April 27, 2020

doi:10.5539/jas.v12n7p146
Accepted: May 29, $2020 \quad$ Online Published: June 15, 2020

URL: https://doi.org/10.5539/jas.v12n7p146

\begin{abstract}
Helicoverpa armigera (Hubner, 1805) (Lepidoptera: Noctuidae) is an insect pest that attacks several cultures and has been a cause of concern in Brazil. The objective of this study was to evaluate parasitism in pupae and caterpillars of H. armigera by Tetrastichus howardi (Olliff, 1893) (Hymenoptera: Eulophidae), in laboratory, as well as checking if $T$. howardi parasitoid has the ability to locate and infect $H$. armigera. In the laboratory, pupae of H. armigera and Diatraea saccharalis (Fabricius, 1794) (Lepidoptera: Crambidae) were exposed to $15 T$. howardi females for 24 hours. Third, fourth and fifth instars of $H$. armigera were exposed to three $T$. howardi females for 24 hours. In the field experiment, cages were installed. Ten caterpillars of the fifth instar of $H$. armigera were released in each cage and waited for the necessary period for them to soak in the soil. After this period, $150 \mathrm{~T}$. howardi females were released in each of four cages and in one cage there was no release of parasitoids. In the laboratory, the percentage of parasitized and emergent pupae was $100 \%$ in both hosts. The life cycle of $T$. howardi in $H$. armigera pupae was 15 days, and for $D$. saccharalis it was 16 days. The progeny was significantly larger for the host $H$. armigera (689.00) compared to D. saccharalis (358.27). The sex ratio was 0.91 and 0.87 for $H$. armigera and $D$. saccharalis, respectively. The longevity of males (25.60 days) and females (26.95 days) in the treatment with $H$. armigera differed from the treatment with $D$. saccharalis, which was 21.70 days for males and 22.95 days for females. For the experiment with $H$. armigera caterpillars, it was found that only two caterpillars from the fifth instar were parasitized with emergence of parasitoids in the pupal phase, with a progeny of 81 individuals; egg-adult cycle was 19.5 days; sex ratio of 0.88 ; male longevity was 19.6 days and for females 20.3 days. Despite the high rate of parasitism of T. howardi in H. armigera pupae in the laboratory, the same did not occur for caterpillars. In the field evaluation, of the total of 50 caterpillars released in the cages, 34 pupae were collected. Of these, 31 pupae had emergence of the $H$. armigera moth. No parasitism by $T$. howardi was found in H. armigera pupae. Further studies should be conducted to evaluate T. howardi parasitism in H. armigera pupae under field conditions.
\end{abstract}

Keywords: biological control, parasitoids, pest insects, soybean crop

\section{Introduction}

As Brazil has reached records of soybean Glycine max (L.) Merrill production with each harvest, it is the second largest soybean producer in the world, with great prospects of being the largest producer (Lima et al., 2019). However, the high production of this grain can be affected by the occurrence of several species of pest insects constantly present in the crop. Among the main species, Helicoverpa armigera (Hübner, 1805) (Lepidoptera: Noctuidae) is of great concern, mainly because the insect in the caterpillar phase feeds preferentially on the plant's reproductive structures, such as inflorescences and pods, causing deformation, rot or fall of the reproductive structure (Ávila et al., 2013). Since 1999, H. armigera was considered a quarantine pest A1 in Brazil. In 2013, its occurrence was officially reported in high infestations in the country, in different states and 
causing damage in many crops (Czepak et al., 2013; Specht et al., 2013; Tay et al., 2013). Integrated Pest Management (IPM) aims to integrate several tactics to optimize insect pest control in a sustainable and economically compatible manner (Prokopy \& Kogan, 2003). Among the control tactics available, biological control is an important tool in the management of $\mathrm{H}$. armigera, mainly because it can be associated with other types of control (Fathipour \& Sedaratian, 2013). After detection of the species in Brazil in 2013, the use of Helicoverpa armigera nucleopolyhedrovirus in crops was approved (HearNPV) as well as the use of the egg parasitoid Trichogramma pretiosum (Riley, 1879) (Hymenoptera: Trichogrammatidae) as the main promising biological control agents for the control of $H$. armigera. In Australia, 45 species of hymenoptera have been reported parasitizing eggs, caterpillars and pupae of Helicoverpa spp. (Johns \& Whitehouse, 2004). In Iran, 36 parasitoids have been reported to be associated with immature forms of H. armigera, with natural biological control levels ranging from 5 to $80 \%$, depending on the crop and the stage of development in which the pest is found (Fathipour \& Sedaratian, 2013). In Brazil, the natural occurrence in H. armigera caterpillars of Archytas marmoratus (Townsend, 1915) (Diptera: Tachinidae) (Guerra et al., 2014) and Campoletis sonorensis (Cameron, 1886) (Hymenoptera: Ichneumonidae), A. incertus (Macquart, 1851) (Diptera: Tachinidae) parasitoids has been recorded, associated with $H$. armigera, in which the larval parasitism rate was higher than $41 \%$ in areas of structured cotton refuge, without the use of chemical insecticides (Luz et al., 2018).

Among the parasitoids found in agroecosystems, Tetrastichus howardi (Olliff, 1893) (Hymenoptera: Eulophidae) is a pupal parasitoid, of Asian origin, widely distributed in northern Australia and northern China and in Western Pakistan (La Salle \& Polaszek, 2007), being introduced from the Philippines to South Africa for biological control of the stem wireworm Chilo partellus (Swinhoe, 1885) (Lepidoptera: Pyralidae) (Kfir et al., 1993). In Brazil, there are reports of parasitism by $T$. howardi in lepidoptera pupae (Pereira et al., 2015) in different cultures, such as corn (Zea mays) and sorghum (Sorghum bicolor) (Cruz et al., 2011), sugarcane (Saccharum officinarum) (Vargas et al., 2011) and kale (Brassica oleracea) (Silva-Torres et al., 2010). And in laboratory conditions, in $H$. armigera pupae, there were good results of parasitism (Oliveira et al., 2016). However, in the agroecosystems, for H. armigera pupa in the soil (Ali \& Choudhury, 2009), it is necessary to develop studies to clarify whether $T$. howardi has the capacity to locate and parasitize the pupae found in the soil. Therefore, the objective of the study was to evaluate the potential use of T. howardi in the control of H. armigera, in pupae and caterpillars, in the laboratory, as well as to verify if the parasitoid $T$. howardi has the capacity to locate and parasite $H$. armigera pupae located in the soil, under field conditions, in soybean culture.

\section{Material and methods}

Three bioassays were performed using $H$. armigera pupae and caterpillars and D. saccharalis pupae from the breeding of the Entomology Laboratory of Embrapa Agropecuária Oeste $\left(22^{\circ} 14^{\prime} \mathrm{S} ; 54^{\circ} 49^{\prime} \mathrm{W}\right)$, bred initially on a modified artificial diet of Greene et al. (1976), and modified diet of Hensley and Hammond (1968), respectively. The $T$. howardi parasitoids used in the experiments were the result of breeding in a natural host $D$. saccharalis (Vargas et al., 2011). The experiments carried out in the laboratory were conducted at the Entomology Laboratory of Embrapa Agropecuária Oeste under controlled conditions of $25 \pm 2{ }^{\circ} \mathrm{C}, 60 \pm 10 \%$ relative humidity and 14 hour photophase. The field experiment was conducted in the experimental area of Fundação MS $\left(22^{\circ} 08^{\prime} \mathrm{S}\right.$; $52^{\circ} 44^{\prime} \mathrm{W}, 425 \mathrm{~m}$ of altitude) located in the municipality of Maracaju, MS.

\subsection{Bioassay 1: Compared Parasitism of T. howardi in Pupae of H. armigera and D. saccharalis}

Helicoverpa armigera pupae $(\mathrm{n}=30)$ with a mass between 0.328 and $0.418 \mathrm{~g}$ and $D$. saccharalis pupae $(\mathrm{n}=30)$ (natural host) with a mass between 0.187 and $0.228 \mathrm{~g}$, both 24 hours after pupation were individualized in flat-bottomed glass tubes $(8.5 \times 2.5 \mathrm{~cm})$ (height $\times$ diameter) and exposed to parasitism by $15 \mathrm{~T}$. howardi females up to 24 hours old. The number of parasitoids per pupa was based on studies carried out by Vargas et al. (2013) and by Oliveira et al. (2016), who in the laboratory obtained $100 \%$ parasitism in pupae of $H$. armigera when exposed to $15 \mathrm{~T}$. howardi females per pupa, providing an increase in the progeny without losing essential biological characteristics in a laboratory breeding. After 24 hours of parasitism, the parasitoids were removed from the tubes and the pupae of $H$. armigera and $D$. saccharalis remained under observation until the emergence of the news parasitoids. The glass tubes containing the pupae were sealed with cotton wool and kept in an air-conditioned room, with a temperature of $25 \pm 2{ }^{\circ} \mathrm{C}$, relative humidity $(\mathrm{RH})$ of $60 \pm 10 \%$ and a 14-hour photophase, until the potential emergence of the parasitoids. Percentage of parasitized pupae and emergent pupae, life cycle duration (egg-adult), progeny (number of parasitoids per pupa), sex ratio (number of females/number of progeny) and longevity of emerged parasitoids were assessed. To evaluate the parasitoids' longevity, 20 females and 10 males of $T$. howardi from each treatment were randomly selected, which were individualized in test tubes containing a drop of honey, where they remained until their death. The sex of $T$. howardi adults was determined according to the morphological characteristics of the antenna according to La Salle and Polaszek 
(2007). The experimental design used was completely randomized, with two treatments (hosts) and 30 repetitions. The use of the natural host, $D$. saccharalis, was thought to be the normal pattern of development of the parasitoid. The data obtained were submitted to homogeneity and normality analysis, taking into account the conditions. Subsequently, the $\mathrm{t}$ test at $5 \%$ significance was performed.

\subsection{Bioassay 2: T. howardi Parasitism in H. armigera Caterpillars and Their Effects on Host Mortality}

Thirty individuals from third, fourth and fifth instars of $H$. armigera were individualized in flat-bottomed glass tubes $(8.5 \times 2.5 \mathrm{~cm})$ (height $\times$ diameter) and exposed to parasitism for 24 hours by three copulated $T$. howardi females with up to 24 hours of age, with 30 caterpillars for each instar, and a control treatment, with caterpillars without exposure to the parasitoid. After the period of exposure to parasitism, the parasitoids were removed from the tubes and an artificial diet was provided for feeding the caterpillars. The glass tubes containing the caterpillars were sealed with cotton wool and kept in an air-conditioned room, with a temperature of $25 \pm 2{ }^{\circ} \mathrm{C}$, relative humidity $(\mathrm{RH})$ of $60 \pm 10 \%$ and a 14 hour photophase, until the potential emergence of the parasitoids. Percentage of parasitized caterpillars and with emergence of parasitoids, the duration of the life cycle (egg-adult), the progeny (number of parasitoids per pupa), the sex ratio (number of females/number of the progeny) and the longevity of emergent parasitoids from parasitized caterpillars were assessed. The effect of parasitism on caterpillar mortality was also evaluated. The experimental design used in a factorial scheme three (caterpillar instar) $\times 2$ (without and with parasitoid) with five replications. Each repetition consisted of a group of six caterpillars. The data obtained were submitted to homogeneity and normality analysis, verifying the need for data transformation. To do this, Taylor's Power Law was followed, reaching the root transformation of $\sqrt{x}+0.5$. After the transformation, the analysis of variance was performed, and the treatment averages compared by the Tukey test at $5 \%$ significance.

\subsection{Bioassay 3: T. howardi Parasitism in H. armigera Pupae, Under Field Conditions, in Soybean Culture}

In an area of approximately 15 hectares sown with soybean cultivar BMX Power RR in no-tillage system, cages made of PVC tube $(1.00 \times 1.00 \mathrm{~m}$ - width $\times$ height $)$ covered with 'voile' fabric, were arranged at random, each covering approximately 12 soybean plants. The bases of the cages, close to the ground, were covered with soil, in order to prevent infestation by undesirable insects, as well as to prevent the escape of insects released inside. During the experiment the soybean plants were between stages R4 and R5.5 (Fehr \& Caviness, 1977). On the upper leaves of the plants, 10 caterpillars of the fifth instar of $H$. armigera were released in each cage, and after a seven-day period, necessary for the caterpillars to pupate in the soil, 150 females of the parasitoid were released in each cage. The number of parasitoids per pupa was based on studies carried out by Vargas et al. (2013) and by Oliveira et al. (2016), as described above. After 24h of the release, pupae were collected from the soil and placed in Petri dishes and kept in the laboratory until the potential emergence of parasitoids. The experiment was conducted in randomized blocks with five replications and cages. In four cages, parasitoids were released and one was left without parasitoids being considered as the control treatment.

\section{Results and Discussion}

\subsection{Compared Parasitism of T. howardi in Pupae of H. armigera and D. saccharalis}

The percentage of pupae with parasitism and adult emergence was $100 \%$ for both hosts evaluated. The life cycle (egg-adult) of $T$. howardi in $H$. armigera pupae was 15 days, and for the host $D$. saccharalis it was 16 days. The progeny was significantly larger for the host $H$. armigera compared to $D$. saccharalis (Table 1 ).

Table 1. Biological aspects of Tetrastichus howardi in pupae of Helicoverpa armigera and Diatraea saccharalis. Temperature of $25 \pm 2{ }^{\circ} \mathrm{C}$, relative humidity (RH) of $60 \pm 10 \%$ and 14 hour photophase

\begin{tabular}{lllll}
\hline \multirow{2}{*}{ Biological parameters } & \multicolumn{2}{c}{ Host } & \multirow{2}{*}{ T test } & CV (\%) \\
\cline { 2 - 4 } & H. armigera & 100 & - & - \\
\hline Parasitism (\%) & 100 & 100 & - & - \\
Emergence (\%) & 100 & $16.00 \pm 0.00$ & - & - \\
Egg-adult cycle (days) & $15.00 \pm 0.00$ & $358.27 \pm 14.54 \mathrm{~b}$ & $238.34^{* *}$ & 15.85 \\
Progeny & $689.00 \pm 15.98 \mathrm{a}$ & $0.87 \pm 0.00 \mathrm{~b}$ & $14.39^{* *}$ & 3.88 \\
Sex ratio & $0.91 \pm 0.00 \mathrm{a}$ & $21.70 \pm 0.30 \mathrm{~b}$ & $106.11^{* *}$ & 3.58 \\
Longevity of ${ }^{* 1}$ & $25.60 \pm 0.30 \mathrm{a}$ & $22.95 \pm 0.25 \mathrm{~b}$ & $152.00^{* *}$ & 4.11 \\
Longevity of $Q^{2}$ & $26.95 \pm 0.18 \mathrm{a}$ & & \\
\hline
\end{tabular}

Note. Means \pm standard error do not differ statistically by $\mathrm{t}$ test at $5 \%$ probability.

** Significant at $1 \%$ probability; ${ }^{1} \delta^{\lambda}$ : Males; ${ }^{2} \circ$ : Females. 
The parasitism and emergence results obtained indicate that $H$. armigera pupae are good hosts for the breeding of the T. howardi species. According to Favero et al. (2013), a high reproductive performance of the parasitoid demonstrates its viability in using the host. In addition, the occurrence of parasitism is fundamental to the biological control applied in IPM and high rates of emergence contribute to the multiplication of parasitoids in mass breeding laboratories, as well as to high-volume releases in order to preserve these species in the field (Dias et al., 2008; Oliveira et al., 2016).

The life cycle duration of the parasitoids was statistically similar between the species studied (Table 1), being shorter than that reported by Costa et al. (2014), who evaluated biological aspects of $T$. howardi in $D$. saccharalis pupae, with a life cycle (egg-adult) duration of 20.26 days, and by Barbosa et al. (2015) when using Erinnyis ello (Linnaeus, 1758) (Lepidoptera: Sphingidae) as a host (20.12 days), and the study was conducted under the same temperature conditions, demonstrating that $H$. armigera does not affect important biological characteristics of the parasitoid, being a suitable host for its multiplication. The duration of the life cycle interferes in the speed of breeding the parasitoid in laboratory; therefore, in the field releases, with a shorter duration of the life cycle favoring a greater number of generations of the parasitoid in less time.

The sex ratio found in this study for H. armigera (0.91) (Table 1) was similar to that reported by Costa et al. (2014) in the host $D$. saccharalis, which was 0.93 females; when the parasitoid $T$. howardi was raised in Tenebrio molitor Linnaeus, 1758 (Coleoptera: Tenebrionidae) pupae, it had a proportion of 0.94 females in the progeny (Oliveira, 2013) and when the host used was E. ello, the sex ratio was 0.96 (Barbosa et al., 2015). Sex ratio values close to one indicate the existence in the progeny of a greater number of females, being important for releases in the field, thus increasing the number of individuals produced in the next generation (Pereira et al., 2009). The sex ratio favors the retention of parasitoids in the crops and the proportion of $60 \%$ of females in the releases is enough for an efficient control (Campos-Farinha et al., 2010; Vacari et al., 2012). Other parasitoids of the Eulophidae family are characterized by the low number of males in the offspring, including Trichospilus diatraeae Cherian \& Margabandhu, 1942 (Hymenoptera: Eulophidae) and Palmistichus elaeisis Delvare \& Lasalle, 1993 (Hymenoptera: Eulophidae) (Chichera et al., 2012; Pastori et al., 2012; Favero et al., 2013).

The longevity of males and females in the treatment with $H$. armigera differed from the treatment with $D$. saccharalis (Table 1). In the host E. ello, the longevity of males and females was 15 and 12 days, respectively (Barbosa et al., 2015). This suggests that $H$. armigera is an alternative quality host, promoting greater longevity of the parasitoid T. howardi. It is noteworthy that the longevity of the parasitoid can result in greater pupal parasitism in potential releases of this biological control agent in the field. The increase in longevity is considered beneficial in the breeding of biological control agents, as it guarantees survival during operational procedures and favors greater stay of natural enemies in cultures (Sorensen et al., 2012; Vargas, 2013).

\subsection{Tetrastichus Howardi Howardi Parasitism in H. armigera Caterpillars and Their Effects on Host Mortality}

Only two caterpillars of $H$. armigera of the fifth instar were parasitized (6.67\%), with emergence of parasitoids (Table 2).

Table 2. Evaluation of parasitism in Helicoverpa armigera caterpillars from different instars and effect on the mortality rates of host caterpillars and pupae. Temperature of $25 \pm 2{ }^{\circ} \mathrm{C}$, relative humidity (RH) of $60 \pm 10 \%$ and 14-hour photophase

\begin{tabular}{|c|c|c|c|c|c|c|c|c|c|}
\hline \multirow{3}{*}{ Catepillar Instar ${ }^{(\mathrm{A})}$} & \multicolumn{3}{|c|}{ Parasitism $^{(\%)}$} & \multicolumn{3}{|c|}{ Caterpillar Mortality (\%) } & \multicolumn{3}{|c|}{ Pupae Mortality (\%) } \\
\hline & \multicolumn{2}{|c|}{ Parasitoid $^{(\mathrm{B})}$} & \multirow{2}{*}{ Mean } & \multicolumn{2}{|c|}{ Parasitoid $^{(\mathrm{B})}$} & \multirow{2}{*}{ Mean } & \multicolumn{2}{|c|}{ Parasitoid $^{(\mathrm{B})}$} & \multirow{2}{*}{ Mean } \\
\hline & Without & With & & Without & With & & Without & With & \\
\hline $3^{\circ}$ & $0 ; 00$ & 0.00 & 0.00 & $6.68 \mathrm{aA}$ & $13.36 \mathrm{aA}$ & $10.02 \mathrm{a}$ & $0.00 \mathrm{aB}$ & $34.00 \mathrm{bA}$ & $17.00 \mathrm{~b}$ \\
\hline $4^{\mathrm{o}}$ & 0.00 & 0.00 & 0.00 & $0.00 \mathrm{bA}$ & $3.34 \mathrm{bA}$ & $1.67 \mathrm{~b}$ & $3.34 \mathrm{aB}$ & $38.04 \mathrm{bA}$ & $20.69 \mathrm{~b}$ \\
\hline $5^{\circ}$ & 0.00 & 6.67 & 3.33 & $0.00 \mathrm{bA}$ & $0.00 \mathrm{bA}$ & $0.00 \mathrm{~b}$ & $3.34 \mathrm{aB}$ & $60.02 \mathrm{aA}$ & $31.68 \mathrm{a}$ \\
\hline Mean & 0.00 & 2.35 & & $2.23 \mathrm{~B}$ & $5.57 \mathrm{~A}$ & & $2.22 \mathrm{~B}$ & $44.02 \mathrm{~A}$ & \\
\hline- & & & & Test $\mathrm{F}^{(\overline{\mathrm{A}})}$ & $10.69 * *$ & & Test $\mathrm{F}^{(\overline{\mathrm{A}})}$ & $2.88^{*}$ & \\
\hline- & & & & Test $\mathrm{F}^{(\mathrm{B})}=$ & $3.10 *$ & & Test $\mathrm{F}^{(\mathrm{B})}$ & $138.66^{* *}$ & \\
\hline- & & & & Test $\mathrm{F}^{(\mathrm{A} * \mathrm{E}}$ & $=1.03^{\mathrm{ns}}$ & & Test $\mathrm{F}^{(\mathrm{A} * \mathrm{E}}$ & $=3.82 *$ & \\
\hline- & & & & $\mathrm{CV}(\%)=$ & $70.84 \%$ & & $\mathrm{CV}(\%)=$ & $32.42 \%$ & \\
\hline
\end{tabular}

Note. Averages followed by the same lowercase letter in the column and uppercase in the row do not differ statistically from each other by the Tukey test at 5\% probability. ${ }^{\text {ns }}$ Not significant; ${ }^{*}$ significant at $5 \%$ probability; ${ }^{* *}$ significant at $1 \%$ probability. The data were transformed into $\sqrt{\mathrm{x}}+0.5$. 
Regarding the parasitism of the two fifth instar caterpillars, the emergence of the parasitoids occurred in the pupal phase, presenting a progeny of 81 individuals; egg-adult cycle was 19.5 days; sex ratio of 0.88 ; male longevity was 19.6 days and for females 20.3 days. The rate of caterpillar parasitism and emergence of parasitoids found in this study was higher than that reported by Pereira et al. (2015), who verified the parasitism of $T$. howardi in different instars of the caterpillar D. saccharalis, which were exposed to seven females of the parasitoid for 96 hours of parasitism, where he identified $2 \%(\mathrm{n}=50)$ of parasitism only in caterpillars of fifth instar, of which, only 14\% had emergence of parasitoids. Emergence of parasitoids occurred in the pupa phase of the host, as reported in this study for H. armigera. Vargas et al. (2013) reported parasitism by $T$. howardi in D. saccharalis caterpillars from second to fifth instar, and one parasitoid female was sufficient to cause the host's mortality, and the percentage of parasitism was influenced by the instars of the caterpillars, and was greater when combined the density of four $T$. howardi females. The low rates of parasitism of $H$. armigera caterpillars by $T$. howardi females suggest that the larval stage of $H$. armigera may have a stronger immune response against this parasitoid, similarly to what was reported for $D$. saccharalis caterpillars parasitized by $T$. howardi (Pereira et al., 2015). Cellular defenses, encapsulation and melanization of endoparasitoid eggs (Pennacchio \& Strand, 2006; Andrade et al., 2010) may be some of the mechanisms involved in this phenomenon. The fact that $H$. armigera caterpillars present a slightly leathery coat may be one of the hypotheses for the low parasitism index, in addition to the caterpillar presenting a very aggressive defensive behavior. The caterpillar, different from the pupal phase, has movements and is able to defend itself from the parasitoid attack (Cônsoli \& Vinson, 2009; Greeney et al., 2012).

Regarding the effects of parasitoid contact with caterpillars, a higher mortality rate was observed in third instar caterpillars (Table 2), possibly due to their smaller size, being more affected by substances injected during oviposition. Caterpillars that died as a result of parasitism acquired a dark color, and a flabby and then rigid integument, as fifth instar caterpillars were often in an intermediate stage between caterpillar and pupa, which was also observed by Vargas et al. (2013) in D. saccharalis caterpillars that were parasitized by $T$. howardi at different instars. Changes in the color and consistency of the body of $H$. armigera caterpillars parasitized by $T$. howardi may be related to the changes promoted by the fluids that are injected during oviposition. These substances cause physiological disturbances that help suppress the host's immune system, causing their death (Danneels et al., 2010; Colinet et al., 2013).

For the H. armigera caterpillars that passed to the pupal phase, differences were verified in relation to the control, with higher mortality rates for the pupae that in the previous phase (caterpillars) had been subjected to contact with the parasitoid (Table 2). Pupae from the fifth instar caterpillars exposed to parasitism had a higher mortality rate $(60.02 \%)$ compared to the third $(34.00 \%)$ and fourth instar $(38.04 \%)$ (Table 2). The pupae that did not originate moths, were hollow, malformed and some were in an intermediate stage between caterpillar and pupa, showing potential stress suffered during the caterpillar phase. The T. howardi female, in some cases, does not cause the immediate death of the D. saccharalis caterpillars, this was evidenced when caterpillars of different instars died after reaching the pupal stage, which may also have occurred with the $H$ armigera caterpillars. It is suggested that the higher mortality of caterpillars and pupae that were exposed to parasitism can be explained by the ability of some parasitoids to inject toxins during oviposition, in order to overcome the immune response by encapsulation of the host (Schmid-Hempel, 2005; Bueno, 2015), which may also have caused the death of the host.

\subsection{Tetrastichus Howardi Howardi Parasitism in H. armigera Pupae, Under Field Conditions, in Soybean Crop}

Of the total of 50 caterpillars released inside the cages, 34 pupae were collected. Of these, three pupae died, and 31 pupae emerged from the $H$. armigera moth. Thus, $T$. howardi parasitism was not found in H. armigera pupae (Table 3).

Table 3. Average percentage of pupae collected from Helicoverpa armigera, pupae parasitized by Tetrastichus howardi and percentage of emergence of $H$. armigera moths, in the field, in soybean culture

\begin{tabular}{lllll}
\hline Parasitoid & Total caterpillars $^{(\mathrm{n})}$ & Pupae Collected $^{(\%)}$ & Pupae Parasitized $^{(\%)}$ & Adult Emergence $^{(\%)}$ \\
\hline Without & 10 & 70.00 & - & 100.00 \\
With & 40 & 67.50 & 0 & 96.00 \\
\hline
\end{tabular}

The search for pupae in the soil was conducted up to $10 \mathrm{~cm}$ deep, as, according to the literature, it is in this range that pupae, in general, are located (Fragoso, 2014). The pupae that were recovered were between three and five 
centimeters deep (Figure 1). This fact corroborates the results found by Martins et al. (2013), in which pupae of $H$. armigera were collected in cotton crop $(\mathrm{n}=78)$, in high infestation of the pest, being located at an average depth of $3.1 \mathrm{~cm}$.

In the search for pupae, initially the straw that was on the ground was carefully removed, as a hypothesis would be that the caterpillar could pupate under the straw, which was not verified, and after that, searched for possible holes that could indicate the pupae location. Only one hole was located where a pupa was collected (Figure 1a and $1 \mathrm{~b})$.
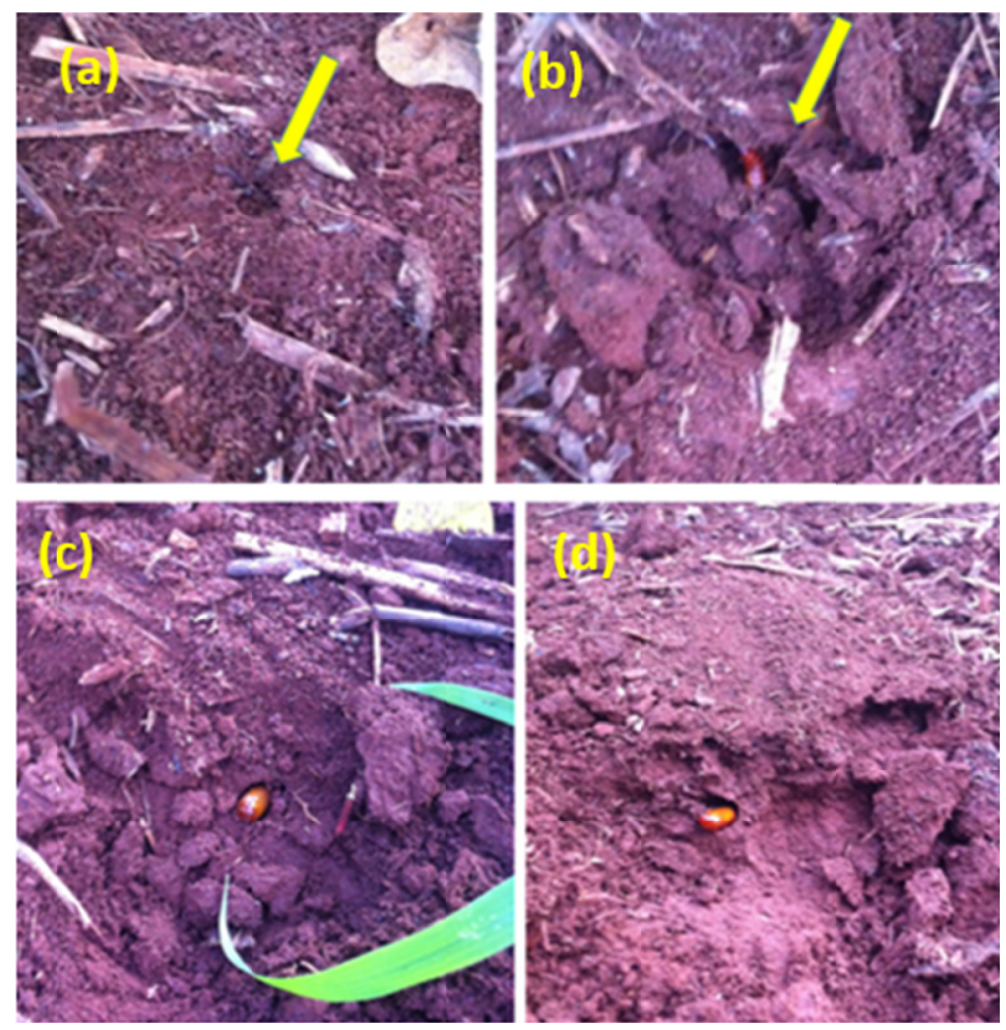

Figure 1. Location of Helicoverpa armigera pupae on the ground (a, b, c, d). Orifice indicating pupal location (a, b). (Photos: Juliana Simonato)

No other holes were observed in the soil indicating the location of pupae, as they were found as the excavation was carried out. A fact that may have interfered was the occurrence of heavy rain $(30 \mathrm{~mm})\left(22^{\circ} 08^{\prime} \mathrm{S}\right.$ and $52^{\circ} 44^{\prime} \mathrm{W}$, $425 \mathrm{~m}$ of altitude) two days before the release of the parasitoids, which may have obstructed the entrance to the pupae access gallery, preventing the parasitoids from reaching them. Perhaps the fact that there was no gallery that would allow the parasitoid to find the pupa made it difficult to locate them and, consequently, parasitism. Barbosa et al. (2018) evaluated parasitism by T. howardi in pupae of D. saccharalis in sugar cane under field conditions, where they found a parasitism rate of $46.4 \%$ when using 102 parasitoid females per pupa. Upon penetrating the sugar cane, the caterpillar D. saccharalis leaves a gallery, where the parasitoid manages to enter and perform the parasitism. However, as the H. armigera pupae are located in the soil, they may obstruct the entrance to the gallery, which prevents the parasitoid from locating the pupae and performing parasitism.

Based on the results obtained, it can be said that $T$. howardi successfully parasitized H. armigera pupae in the laboratory. However, $H$. armigera parasitism in caterpillars was not efficient, but it cannot be ruled out. With all, it was observed that caterpillars that were exposed to parasitism had a higher mortality rate, mainly in the pupa phase, suggesting that the effect of parasitism may have negatively affected this phase. Taking this fact into account, and that the parasitoid had a longevity of around 25 days, in field conditions it would be able to act in the different phases it encountered, parasitizing caterpillars of different instars, causing mortality even in the caterpillar phase and in the pupa phase of the host, being a contribution to the biological control of this pest. Studies focused on evaluating parasitism in H. armigera caterpillars, testing various densities of parasitoids, as well as the longer time of exposure to parasitism, may be conducted, in order to verify if the parasitoid is 
efficient in the caterpillar phase. The efficiency of parasitism in pupae supports future evaluations for mass breeding of this parasitoid using pupae from this host. Although $H$. armigera parasitism by $T$. howardi did not occur under the conditions of this study, in the field, in soybean culture, it is important to carry out new experiments to validate this information.

\section{References}

Ali, A., \& Choudhury, R. A. (2009). Some biological characteristics of Helicoverpa armigera on chickpea. Tunisian Journal of Plant Protection, 4(1), 99-106.

Andrade, G. S., Serrão, J. E., Zanuncio, J. C., Zanuncio, T. V., Leite, G. L. D., \& Polanczyk, R. A. (2010). Immunity of an alternative host can be overcome by higher densities of its parasitoids Palmistichus elaeisis and Trichospilus diatraeae. PLoS ONE, 5, 1-7. https://doi.org/10.1371/journal.pone.0013231

Ávila, C. J., Vivan, L. M., \& Tomquelski, G. V. (2013). Ocorrência, aspectos biológicos, danos e estratégias de manejo de Helicoverpa armigera (Hübner) (Lepidoptera: Noctuidae) nos sistemas de produção agrícolas. Circular técnica, 23 (p. 12). Dourados: Embrapa Agropecuária Oeste.

Barbosa, R. H., Kassab, S. O., Pereira, F. F., Rossoni, C., Costa, D. P., \& Berndt, M. A. (2015). Parasitism and biological aspects of Tetrastichus howardi (Hymenoptera: Eulophidae) on Erinnyis ello (Lepidoptera: Sphingidae) pupae. Ciência Rural, 45(2), 185-188. https://doi.org/10.1590/0103-8478cr20130896

Barbosa, R. H., Pereira, F. F., Motomiya, A. V. A., Kassab, S. O., Rossoni, C., Torres, J. B., ... Pastori, P. L. (2018). Tetrastichus howardi density and dispersal toward augmentation biological control of sugarcane borer. Neotropical Entomology, 48(2), 323-331. https://doi.org/10.1007/s13744-018-0646-z

Bueno, M. N. (2015). Bases biológicas para utilização de Trichospilus diatraeae (Hymenoptera: Eulophidae) para controle de Helicoverpa armigera (Lepidoptera: Noctuidae) (49f. Dissertação (Mestrado em Agronomia), Universidade Estadual Paulista "Júlio De Mesquita Filho", Botucatu-SP).

Campos-Farinha, A. E. C., Chaud-Netto, J., \& Gobbi, N. (2010). Biologia reprodutiva de Cotesia flavipes (Cameron) (Hymenoptera: Braconidae). IV. Discriminação entre lagartas parasitas e não parasitadas de Diatraea saccharalis Fabricius (Lepidoptera: Pyralidae) tempo de desenvolvimento e razão sexual dos parasitoides. Arquivos do Instituto Biológico, 67, 229-234.

Chichera, R. A., Pereira, F. F., Kassab, S. O., Barbosa, R. H., Pastori, P. L., \& Rossoni, C. (2012). Capacidade de busca de Trichospilus diatraeae e Palmistichus elaeisis (Hymenoptera: Eulophidae) em pupas de Diatraea saccharalis (Lepidoptera: Crambidae). Interciencia, 37, 852-856.

Colinet, D., Mathé-Hubet, H., Allemand, R., Gatti, J. L., \& Poirié, M. (2013). Variability of venom components in immune suppressive parasitoid wasps: From a phylogenetic to a population approach. Journal of Insect Physiology, 59, 205-212. https://doi.org/10.1016/j.jinsphys.2012.10.013

Cônsoli, F. L., \& Vinson, S. B. (2009). Parasitoides (Hymenoptera). In A. R. Panizzi \& J. R. P. Parra (Eds.), Bioecologia e nutrição de insetos: Base para o manejo integrado de pragas (pp. 837-873). Brasília: Embrapa Informação Tecnológica.

Costa, D. P., Pereira, F. F., Kassab, S. O., Rossoni, C., Favero, K. \& Barbosa, R. H. (2014). Reprodução de Tetrastichus howardi (Hymenoptera: Eulophidae) em pupas de Diatraea saccharalis (Lepidoptera: Crambidae) de diferentes idades. Revista de Ciências Agrárias, 57, 67-71. https://doi.org/10.4322/rca. 2013.067

Cruz, I., Redoan, A. C., Silva, R. B., Figueiredo, M. L. C., \& Penteado-Dias, A. M. (2011). New record of Tetrastichus howardi (Olliff) as a parasitoid of Diatraea saccharalis (Fabr.) on maize. Scientia Agricola, 68, 52-254. https://doi.org/10.1590/S0103-90162011000200017

Czepak, C., Albernaz, K. C., Vivan, L. M., Guimarães, H. O., \& Carvalhais, T. (2013). Primeiro registro de ocorrência de Helicoverpa armigera (Hübner) (Lepidoptera: Noctuidae) no Brasil. Pesquisa Agropecuária Tropical, 43, 10-113. https://doi.org/10.1590/S1983-40632013000100015

Danneels, E. L., Rivers, D. B., \& Graaf, D. C. (2010). Venom proteins of the parasitoid wasp Nasonia vitripennis: Recent discovery of an untapped pharmacopee. Toxins, 2, 494-516. https://doi.org/10.3390/toxins2040494

Dias, N. S., Parra, J. R. P., \& Lima, T. C. C. (2008). Seleção de hospedeiro alternativo para três espécies de tricogramatídeos neotropicais. Pesquisa Agropecuária Brasileira, 43, 1467-1473. https://doi.org/10.1590/ S0100-204X2008001100004 
Fathipour, Y., \& Sedaratian, A. (2013). Integrated management of Helicoverpa armigera in soybean cropping systems. Soybean - Pest resistence (pp. 231-280). Cairo, Egypt. https://doi.org/10.5772/54522

Favero, K., Pereira, F. F., Kassab, S. O., Oliveira, H. N. D., Costa, D. P., \& Zanuncio, J. C. (2013). Biological characteristics of Trichospilus diatraeae (Hymenoptera: Eulophidae) are influenced by the number of females exposed per pupa of Tenebrio molitor (Coleoptera: Tenebrionidae). Florida Entomologist, 96(2), 583-589. https://doi.org/10.1653/024.096.0224

Fehr, W. R., \& Caviness, C. E. (1977). Stages of soybean development (Special Report 80, p. 11). Ames: Iowa State University of Science and Technology.

Fragoso, D. B. (2014). Helicoverpa armigera: Conhecer para combater! Fronteira Agrícola, Informativo técnico-Núcleo de Sistemas Agrícolas da Embrapa Pesca e Aquicultura, 1.

Greene, G. L., Leppl, N. C., \& Dickerson, W. A. (1976). Velvet bean caterpillar: a rearing procedure and artificial medium. Journal of Economic Entomology, 69, 487-488. https://doi.org/10.1093/jee/69.4.487

Greeney, H. F., Dyer, L. A. S., \& Milanich, A. M. (2012). Feeding by lepidopteran larvae is dangerous: A review of caterpillars chemical, physiological, morphological, and behavioral defenses against natural enemies. Invertebrate Survival Journal, 9, 7-34.

Guerra, W. D., Guerra, A. L. L. D., Ribas, L. N., Gonçalves, R. M., \& Mastrangelo, T. (2014). Molecular identification of a parasitic fly (Diptera: Tachinidae) from the introduced Helicoverpa armigera (Lepidoptera: Noctuidae) in Brazil. Entomology, Ornithology and Herpetology, 3(3), 1-4. https://doi.org/ 10.4172/2161-0983.1000131

Hensley, S. D., \& Hammod, A. H. (1968). Laboratory techniques for rearing the sugar cane borer on an artificial diet. Journal of Economic Entomology, 61, 1742-1743. https://doi.org/10.1093/jee/61.6.1742

Johns, C. V., \& Whitehouse, M. E. A. (2004). Mass rearing of two larval parasitoids of Helicoverpa spp. (Lepidoptera: Noctuidae): Netelia product (Brulle) and Heteropelma scaposum (Morley) (Hymenoptera: Ichneumonidae) for field release. Australian Journal of Entomology, 43, 83-87. https://doi.org/10.1111/ j.1440-6055.2004.00402.x

Kfir, R., Gouws, J., \& Moore, S. D. (1993). Biology of Tetrastichus howardi (Olliff) a facultative hyperparasite of stem borers. Biocontrol Science and Technology, 3, 149-159. https://doi.org/10.1080/0958315930 9355271

La Salle, J., \& Polaszek, A. (2007). Afrotropical species of the Tetrastichus howardi species group (Hymenoptera: Eulophidae). African Entomology, 15, 45-56. https://doi.org/10.4001/1021-3589-15.1.45

Lima, M., Junior, C. A. S., Rausch, L., Gibbs, H. K., \& Johann, J. A. (2019). Demystifying sustainable soy in Brazil. Land Use Policy, 82, 349-352. https://doi.org/10.1016/j.landusepol.2018.12.016

Luz, P. M. C., Moraes, S. V. P., López, J. M. P., Luz, J. R. P., Dias, A. M. P., Specht, A., \& Diniz, I. R. (2018). Parasitoid associated with of Helicoverpa armigera in refuge areas of cotton, in Western Bahia, Brazil. Ciência Rural, 48(1), 1-4. https://doi.org/10.1590/0103-8478cr20170250

Martins, M. C., Santos, G. B., Kischel, E., Fumagalli, F. P., Brugnera, P., \& Tamai, M. A. (2013). Exame minucioso. Revista Cultivar Grandes Culturas, 174, 32-33.

Oliveira, F. G. (2013). Multiplicação de Tetrastichus howardi (Hymenoptera: Eulophidae) em pupas de Tenebrio molitor (Coleoptera: Tenebrionidae) e de Diatraea saccharalis (Lepidoptera: Crambidae) (63f., Dissertação, Mestrado em Entomologia e Conservação da Biodiversidade, Universidade Federal da Grande Dourados, Dourados-MS).

Oliveira, H. N., Simonato, J., Glaeser, D. F., \& Pereira, F. F. (2016). Parasitism of Helicoverpa armigera pupae (Lepidoptera: Noctuidae) by Tetrastichus howardi and Trichospinus diatraeae (Hymenoptera: Eulophidae). Semina Ciências Agrárias, 37(1), 111-115. https://doi.org/10.5433/1679-0359.2016v37n1p111

Pastori, P. L., Zanuncio, J. C., Silva, R. O., Pereira, F. F., Azambuja, R., \& Pereira, J. M. M. (2012). Reprodução de Trichospilus diatraeae Cherian \& Margabandhu (Hymenoptera: Eulophidae) em pupas de Anticarsia gemmantalis Hübner (Lepidoptera: Noctuidae) em relação a idade do parasitoide e do hospedeiro. EntomoBrasilis, 5, 37-42. https://doi.org/10.12741/ebrasilis.v5i1.155

Pennacchio, F., \& Strand, M. R. (2006). Evolution of developmental strategies in parasitic Hymenoptera. Annual Review of Entomology, 51, 233-258. https://doi.org/10.1146/annurev.ento.51.110104.151029 
Pereira, F. F., Kassab, S. O., Vargas, E. L., Calado, V. R. F., Oliveira, H. N., \& Zanuncio, J. C. (2015). Parasitism and emergence of Tetrastichus howardi (Hymenoptera: Eulophidae) on Diatraea saccharalis (Lepidoptera: Crambidae) larvae, pupae and adults. Florida Entomologist, 98(1), 377-380. https://oi.org/10.1653/ 024.098.0164

Pereira, F. F., Zanuncio, J. C., Serrão, J. E., Pastori, P. L., \& Ramalho, F. S. (2009). Reproductive performance of Palmistichus elaeisis (Hymenoptera; Eulophidae) with previously refrigerated pupae of Bombyx mori (Lepidoptera; Bombycidae). Brazilian Journal of Biology, 69(3), 865-869. https://doi.org/10.1590/ S1519-69842009000400014

Prokopy, R. J., \& Kogan, M. (2003). Integrated pest management. In V. H. Resh \& R. T. Cardé (Ed.), Encyclopedia of Insects (pp. 4-9). New York, Academic Press.

Schmid-Hempel, P. (2005). Evolutionary ecology of insect immune defenses. Annual Review of Entomology, 50, 529-551. https://doi.org/10.1146/annurev.ento.50.071803.130420

Silva-Torres, C. S. A., Ponte, I. V. A. F., Torres, J. B., \& Barros, R. (2010). New records of natural enemies of Plutella xylostella (L.) (Lepidoptera: Plutellidae) in Pernambuco, Brazil. Neotropical Entomology, 39, 835-838. https://doi.org/10.1590/S1519-566X2010000500028

Sorensen, J. G., Addison, M. F., \& Terblanche, J. S. (2012). Mass-rearing of insects for pest management: Challenges, synergies and advances from evolutionary physiology. Crop Protection, 38, 87-94. https://doi.org/10.1016/j.cropro.2012.03.023

Specht, A., Sosa-Gómez, D. R., Paula-Moraes, S. V., \& Yano, S. A. C. (2013). Identificação morfológica e molecular de Helicoverpa armigera (Lepidoptera: Noctuidae) e ampliação de seu registro de ocorrência no Brasil. Pesquisa Agropecuária Brasileira, 48(6), 689-692. https://doi.org/10.1590/S0100-204X2013 000600015

Tay, W. T., Soria, M. F., Walsh, T., Thomazoni, D., Silvie, P., Behere, G. T., Anderson, C., \& Downes, S. (2013). A brave New World for an Old World pest: Helicoverpa armigera (Lepidoptera: Noctuidae) in Brazil. PLoS ONE, 8(11), 1-7. https://doi.org/10.1371/journal.pone.0080134

Vacari, A. M., De Bortoli, S. A., Borba, D. F., \& Martins, M. I. E. G. (2012). Quality of Cotesia flavipes (Hymenoptera: Braconidae) reared at different host densities and the estimated cost of its commercial production. Biological Control, 63, 102-106. https://doi.org/10.1016/j.biocontrol.2012.06.009

Vargas, E. L. (2013). Parasitismo e desenvolvimento e Tetrastichus howardi (Hymenoptera: Eulophidae) em lagarta e pupa de Diatraea saccharalis (Lepidoptera: Crambidae) (89f. Tese, Doutorado em Agronomia, Produção Vegetal, Universidade Federal da Grande Dourados, Brazil).

Vargas, E. L., Pereira, F. F., Tavares, M. T., \& Pastori, P. L. (2011). Record of Tetrastichus howardi (Hymenoptera: Eulophidae) parasitizing Diatraea sp. (Lepidoptera: Crambidae) in sugarcane crop in Brazil. Entomotropica, 26, 135-138.

\section{Copyrights}

Copyright for this article is retained by the author(s), with first publication rights granted to the journal.

This is an open-access article distributed under the terms and conditions of the Creative Commons Attribution license (http://creativecommons.org/licenses/by/4.0/). 